\title{
Parametric improvement for the ingestion dose module of the European ARGOS and RODOS decision support systems
}

\author{
K.G. Andersson ${ }^{1}$, S.P. Nielsen ${ }^{1}$, H. Thørring ${ }^{2}$, H.P. Joensen ${ }^{3}$, M. Isaksson ${ }^{4}$, \\ E. Kostiainen ${ }^{5}$, V. Suolanen ${ }^{6}$ and S.E. Pálsson ${ }^{7}$ \\ ${ }^{1}$ Risø National Laboratory for Sustainable Energy, Technical University of Denmark, \\ P.O. Box 49, DK-4000 Roskilde, Denmark \\ ${ }^{2}$ Norwegian Radiation Protection Authority, P.O. Box 55, 1332 Østerås, Norway \\ ${ }^{3}$ Faculty of Science and Technology, University of Faroe Islands, Nóatún 3, \\ FO 100 Tórshavn, Faroe Islands \\ ${ }^{4}$ University of Gothenburg, Sahlgren Academy, Institute of Clinical Sciences, Department \\ of Radiation Physics; SU/Sahlgrenska, SE 41345 Göteborg, Sweden \\ ${ }^{5}$ Radiation and Nuclear Safety Authority, P.O. Box 14, FI-00881 Helsinki, Finland \\ ${ }^{6}$ VTT Technical Research Centre, P.O. Box 1000, FI-02044 VTT Espoo, Finland \\ ${ }^{7}$ Icelandic Radiation Safety Authority, Raudararstig 10, IS-150 Reykjavik, Iceland
}

\begin{abstract}
The European decision support systems ARGOS and RODOS rely on the ECOSYS model for prognoses of ingestion doses. ECOSYS needs an update of various parameter values to provide reliable estimates. This paper reports on some results of a Nordic initiative to derive parameter values that are specific to Nordic conditions, as well as to improve generic parameter values in ECOSYS, taking into account the host of useful measurement data accumulated since ECOSYS was created.
\end{abstract}

\section{INTRODUCTION}

More than any other tools, the ARGOS and RODOS decision support systems constitute the prognostic 'spine' in European preparedness against accidents at nuclear installations. The systems deliver crucial information that can be used for justification and optimisation of countermeasure strategies during different time phases, thus assisting in effectively reducing the adverse health impacts through different pathways. The module for estimating ingestion dose is in both systems based on the ECOSYS model [1], which was developed in the 1980's. It is however problematic that contrary to recommendations from its originators this model has undergone very few parametric changes by its many users since it was created, and default parameter values, which are generally used uncritically, do not make use of the huge amount of radioecological data that has been generated over the latest few decades. Prognoses made with the model 'as is' are therefore not founded on the best knowledge of today. On the basis of investigations made under the Nordic research activity (NKS-B-PardNor), new and improved parameterisation is suggested for parameters such as deposition velocities, natural contaminant weathering rates from plants, and soil-to-plant transfer factors, as well as leaching rates, fixation rates and desorption rates of soil contaminants. An other problem with the use of the ingestion dose modules in the two decision support systems is that parameters are generally not 'customised' locally to reflect the specific conditions in the country or area for which the system is to be used. This means that parameters describing for instance dietary habits, import fractions of food items, animal feeding regimes, seasonal plant development and soil characteristics are not properly specified, and analyses made under the NKS-BPardNor activity have demonstrated that this can lead to serious prognostic errors. Examples are given of the findings of the NKS-B-PardNor work group. 


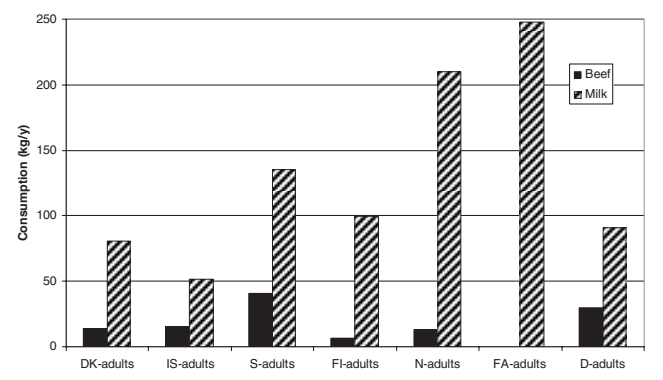

Figure 1. Consumption rates of beef and milk in various countries. * Note that these milk consumption rates do not include cream, cheese and butter.

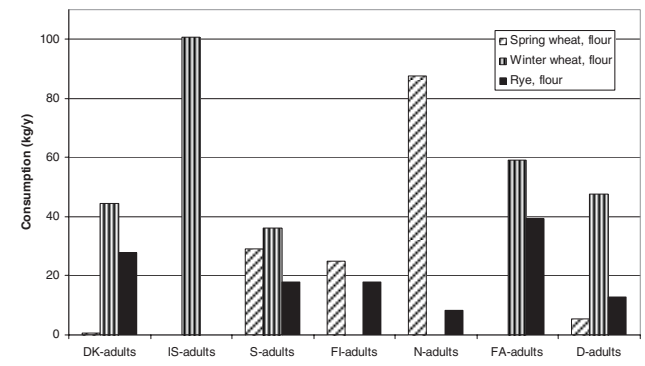

Figure 2. Consumption rates of spring wheat flour, winter wheat flour and rye flour in various countries. * Note that the high rate shown under Icelandic spring wheat is a total consumption rate for all cereal flour.

\section{METHODS AND RESULTS}

\subsection{Area-specific parameters}

\subsubsection{Human diets}

Consumption habits can vary considerably between countries, depending on, e.g., the climate and local tradition. It is essential that the data applied in the model adequately reflects current location-specific habits. A data survey was made in all the Nordic countries [2]. Fairly recent dietary survey data (newer than 1997) was found for all except the Faroe Islands, where the newest data was from 1982. Figures 1 and 2 show the consumption of respectively beef and meat, and various cereal flours in Denmark (DK), Iceland (IS), Sweden (S), Finland (FI), Norway (N) and Faroe Islands (FA), as well as the German ECOSYS defaults for comparison. As can be seen, beef and milk consumption varies by almost a factor of 5 between Nordic countries. The Chernobyl accident, as well as the recent Fukushima accident, has demonstrated the radiological importance of the rapid milk food chain. It is important also to note that whereas Denmark, Norway, Finland and Sweden have fairly self-sufficient production of wheat flour, all flour consumed in the Faroe Islands and Iceland is imported. Due to differences in climate, in the northernmost countries (Norway and Finland), practically all wheat is spring wheat, whereas in Denmark, Sweden and Germany, the majority of the wheat produced/consumed is winter wheat. This means that if a contamination occurs in the spring, the wheat plants will in Finland and Norway have undergone very little development, whereas in the more southern countries, where sowing took place already in the previous autumn, and the warmer weather would lead to a more rapid plant development, the wheat plants could be quite mature, and receive a comparatively considerably higher contaminant deposition. This would greatly affect wheat flour contamination levels in the first harvest. As for rye flour, the consumption is for instance seen to be $4-5$ times as high in the Faroe Islands as in Norway. 


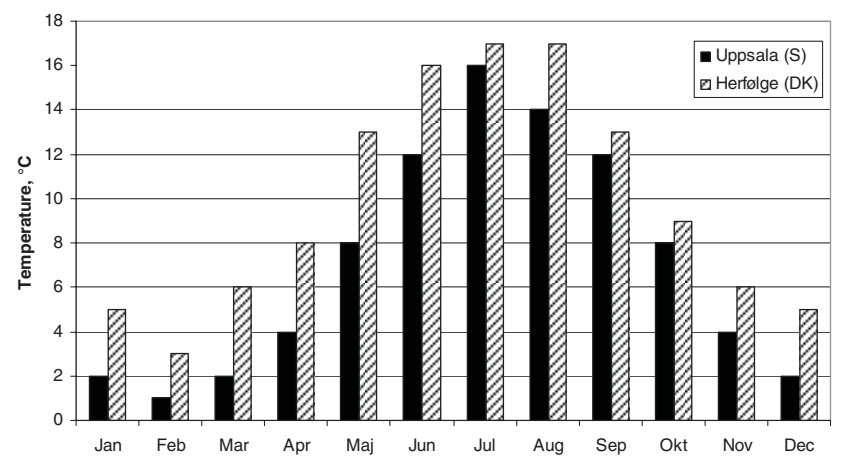

Figure 3. Monthly average soil temperature at $10 \mathrm{~cm}$ depth in Uppsala, Sweden and Herfølge, Denmark. Data for both locations recorded in 2005 .

\subsubsection{Animal feeding}

Also differences in Nordic animal feeding regimes can have great bearing on doses received after a contaminating incident. For instance, Danish lactating cattle are generally kept in stables all year round, and fed with stored products (maize and grass silage), whereas Norwegian lactating cattle are grazing between the $1^{\text {st }}$ of June and the $15^{\text {th }}$ of September. ECOSYS calculations show that if an accident occurs in the beginning of June, the caesium concentrations in Norwegian milk, cream, butter and beef would even after six months all be one or two orders of magnitude higher than the corresponding in Danish products, unless countermeasures had been introduced. For other animals, the feeding regimes are qualitatively similar for different countries, but due to different climates, the differences between indoor and outdoor feeding periods can be significant, and if a contamination occurs in the intermediate time period, the resultant differences in animal food contamination levels can be very large. For instance Norwegian lactating cattle begin their grazing season nearly a month later than assumed in the Bavarian ECOSYS defaults, and end it nearly two months earlier [2].

\subsubsection{Crop development periods}

As already mentioned above, different climates will offer different conditions for plant growth, and there are periods of the year where there are great differences between Nordic countries in the maturity of plants. Direct deposition to mature crops will generally give high crop food contamination levels in the first year harvest. Also, the overall dry deposition to an area with standing crops will be much higher than that to a bare soil area, due to the large leaf area. It is thus very important to take into account the plant development stage at the time of deposition, and not just apply ECOSYS default values blindly, as they only apply for climates similar to south Germany. The state of growth of all crops is in ECOSYS determined by the leaf area index (LAI), which is defined as the total one-sided leaf area of plants per unit soil area covered by the plant. The Danish Institute of Agricultural Sciences has, on the basis of large amounts of measurement data, developed a simple empirical model/data set describing the seasonal variation of LAI for a number of different crops [3]. The key variables are here the sowing time, soil temperature and harvest time. Values are given for normal and low fertilisation status. The model can thus be applied for different climates, and should in principle be applicable also for other Nordic conditions, where the variation over the year in soil temperature is known. This was tested in practice using data for Nordic locations, where seasonal leaf area variation has been measured. Fig. 3 shows a comparison of monthly average temperatures recorded in Uppsala, Sweden, and Herfølge, Denmark. As can be seen, the Uppsala temperatures are over the entire year some $1-5^{\circ} \mathrm{C}$ lower than the Danish. 


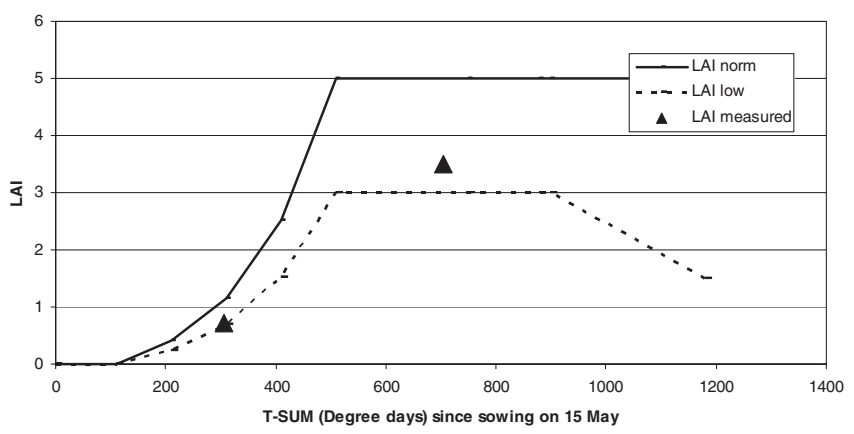

Figure 4. Seasonal variation in LAI for barley at Uppsala, Sweden. Model curves compared with two measurement data points.

The results of applying the soil temperature data from Uppsala in the Danish model for barley can be compared with measured values of LAI for barley in Uppsala, at two different times of the year: the 18th of June and the 13th of July [4]. Fig. 4 shows the development of LAI over a season, modelled on the background of the Danish dataset and the soil temperature data reported for Uppsala, assuming respectively normal and low fertilisation status. T-SUM represents a summation over days multiplied by the average daily values of temperature (degree days). As can be seen, the model curves are in good agreement with the measured LAI data for the Uppsala location (denoted by the triangles in fig. 4), indicating that the Danish model dataset may also be applied for other localities with (slightly) different climates. However, it should be noted that in the northernmost areas of the Nordic countries, crop sort varieties are sometimes specially selected to give rapid development, to make the most of the short growing season. The sowing time in Uppsala was assumed to be the date where the soil temperature reaches about $8^{\circ} \mathrm{C}$ (e.g., [5, 6]). This occurs about one month later in Uppsala than in Herfølge.

\subsection{Generic parameters}

\subsubsection{Deposition velocities}

An important generic (i.e. country invariant) parameter that badly needs improvement in the ECOSYS model is the dry deposition velocity of contaminants to crops. A key problem in ECOSYS is that deposition velocities of aerosols are not assumed to vary with aerosol size. However, due to the different deposition mechanisms (e.g., Brownian diffusion, gravitational settling), for instance deposition velocities to soil of $0.7 \mu \mathrm{m}$ particles formed by condensation of evaporated volatile elements and $20 \mu \mathrm{m}$ particles formed by physical fractionation of more refractory materials in an explosion generally differ by more than two orders of magnitude [7]. It should also be noted that although the ECOSYS default value for aerosols to crops of $2 \mathrm{~mm} / \mathrm{s}$ has been claimed to relate particularly well to particles in the $0.1-1 \mu \mathrm{m}$ range [1], it is actually most suitable for particles of the ca. $5 \mu \mathrm{m}$ range. It should of course be stressed that ECOSYS was as mentioned above parameterised back in the pre-Chernobyl era, where few measurements of direct relevance to aerosol deposition on crops had been made. It is however problematic that such data has still not been included in the versions of ECOSYS implemented in ARGOS and RODOS, as it clearly has great influence on the reliability of dose predictions. Some years ago, a new inhabited areas model in ARGOS and RODOS (ERMIN) was implemented [8], which distinguished between deposition velocities of aerosols of different size groups (although it was in practice only parameterised for two of the originally scheduled four groups). A similar effort is urgently needed for the crop deposition model. A literature survey and interpretation has therefore been conducted, which will be reported on in detail in a separate paper [9]. This review showed that the influence of crop species was comparatively small, even though some variation was 
reported by workers who undertook experiments on very different crop types. It was for instance found that a value that reasonably represents the deposition velocity to crops of $0.7 \mu \mathrm{m}$ particles would be about an order of magnitude smaller than the ECOSYS aerosol default value. Also for radioiodine gases (elemental as well as organic), the ECOSYS default deposition velocities should be changed, as they are much too high.

Also wet scavenging coefficients are strongly dependent on the contaminant aerosol size distribution, and this also needs to be taken into account in decision support systems [9].

\subsubsection{Natural weathering rates}

A literature review has also been made of the natural weathering processes that govern the decline in crop contamination in the early phase after a contaminating incident. Also this review is presented in detail elsewhere [9]. The weathering processes can have considerable influence on the contaminant concentrations in the first crop harvest after the occurrence of the contamination. ECOSYS by default assumes a weathering half-life of 25 days for all contaminants regardless of their physicochemical forms. This value was in view of the recent literature survey found to be representative only of periods with dry weather conditions. In case of prolonged precipitation an approximately ten times lower value can be reasonable to assume for most contaminants. The first rain shower should be expected to wash off all elemental iodine deposited on crops. As elemental iodine concentrations will often be very high in the early phase after a large nuclear power plant accident (re Chernobyl and Fukushima), this is important to consider in estimating early doses. Therefore, it would strengthen the prognostic value of decision support systems to take into account the actual or expected precipitation over the relevant period (a few weeks). Weather prognoses, which are anyway applied in the deposition modelling in the decision support systems, would be very useful also in this context.

\subsubsection{Soil-to-plant transfer factors}

Improvement of soil-to-plant transfer factors in ECOSYS is needed for two reasons. Firstly, as for other parameters in ECOSYS, the underlying data that the parameterisation was based on is old, and a review of data generated over the latest decades is required. The other problem is that ECOSYS currently does not distinguish between different soil types, which can also lead to considerable errors due to, e.g., the very different retention of contaminants like radiocaesium in sand and in clayey soils, where the caesium cations are very efficiently and virtually irreversibly fixed on 'frayed edge' sites [10]. An improvement that would fit well with previously suggested database and graphical user interface extensions in ARGOS would involve a rough classification of soil types in categories like sand, loam, clay and organic soils. Also, this level of detail would comply well with that applied in a recent comprehensive IAEA review report [11], which would be an important source in the derivation of most of the required parameter values. Not very surprisingly, the IAEA report in some cases suggests transfer factors that differ by more than an order of magnitude from the ECOSYS default values. Table 1 shows a comparison, for just two of the many plant types considered in ECOSYS, of ECOSYS transfer factors for radiocaesium with those recommended in the IAEA report.

Of course, since different areas will often have different soil types (and some special Icelandic soils undoubtedly demand a separate transfer factor classification), soil-to-plant transfer factors are essentially area specific. An examination was made of the availability in each of the Nordic countries of gridded data that could facilitate the needed simple soil classification. For most of the Nordic countries, a soil classification exists, based on textural analysis of soil samples on a detailed grid, although at different grid resolution. For instance, in Finland, the sampling density is ca. 59 sampling locations per 1000 hectares, whereas the grid with highest resolution in Denmark has about 14 sampling locations per 1000 hectares, and in Sweden, some 3100 sampling locations are scattered over the entire country. For the Faroes, soil data is only available for a limited number of localities. 
Table 1. Two examples of corresponding radiocaesium soil-to-plant transfer factors (concentration ratios, Fv) in the ECOSYS model and in IAEA TECDOC 1616.

\begin{tabular}{lccc}
\hline Plant group & Soil type & $\begin{array}{c}\text { Fv in ECOSYS } \\
\mathrm{Bq} \mathrm{kg}^{-1} \mathrm{fw} / \\
\mathrm{Bq} \mathrm{kg}^{-1} \mathrm{dw}\end{array}$ & $\begin{array}{c}\text { Fv from TECDOC 1616 } \\
\mathrm{Bq} \mathrm{kg}^{-1} \mathrm{fw} / \\
\mathrm{Bq} \mathrm{kg}^{-1} \mathrm{dw}\end{array}$ \\
\hline Grass (intensive farming) & All & 0.05 & 0.02 \\
& Sand & & 0.01 \\
& Loam & & 0.002 \\
& Clay & & 0.06 \\
\hline Organic & All & 0.02 & 0.01 \\
& Sand & & 0.007 \\
& Loam & & 0.002 \\
& Clay & & 0.002 \\
\hline Organic & & \\
\hline
\end{tabular}

\section{CONCLUSIONS}

An effort has been made to revise the input parameters in the ECOSYS model, which governs the ingestion dose estimates in the widely used ARGOS and RODOS decision support systems. Dietary parameters, including information on imported fractions of each dietary constituent, as well as areaspecific data on animal feeding regimes have been derived for each of the Nordic countries for inclusion in Nordic customised versions of ECOSYS. Also the variation between different climates in seasonal crop development is a factor that is important to consider in local ECOSYS customisation, and here, a simple soil-temperature-LAI relationship may be useful. Also revisions of some parameters that are independent of the location (deposition velocities, natural weathering rates and soil-to-plant transfer factors) were suggested on in this paper. All parametric revisions (and also others reported elsewhere) were found to have importance for ECOSYS prognoses, at least under some circumstances, and should be implemented in the European decision support systems to enable as reliable prognoses as possible.

\section{References}

[1] H. Müller, G. Pröhl, Health Phys. 64(3), 232 (1993).

[2] S.P. Nielsen, K.G. Andersson (eds.), NKS report NKS-174, (Nordic Nuclear Safety Research (NKS), Roskilde, Denmark, 2008).

[3] Plauborg, F. \& Olesen, J.E., Tidsskrift for Planteavls Specialserie (in Danish), 2113 (1991).

[4] H. Thorgeirsson, H. Søgaard, Agric. and Forest Meteorology 98-99, 479 (1999).

[5] Farsø Markservice (2006). www.fmmajs.dk/kontakt.html.

[6] Dansk Landbrugsrådgivning (2008). www.planteinfo.dk.

[7] T.A. McMahon, P.J. Denison, Atmosph. Environ. 13, 571 (1979).

[8] T.W. Charnock, J.A. Jones, L.N. Singer, K.G. Andersson, J. Roed, S. Thykier-Nielsen, T. Mikkelsen, P. Astrup, J.C. Kaiser, H. Müller, G. Pröhl, W. Raskob, S.C. Hoe, L.H. Jacobsen, L. Schou Jensen, F. Gering, Radioprotection 44 (5), 407 (2009).

[9] K.G. Andersson, S.P. Nielsen, H. Thørring, H.S. Hansen, H.P. Joensen, M. Isaksson, E. Kostiainen, V. Suolanen, S.E. Pálsson, Revision of deposition and weathering parameters for the ingestion dose module (ECOSYS) of the ARGOS and RODOS decision support systems, submitted for publication in J. Environ. Radioactivity (2011).

[10] K.G. Andersson, in Airborne radioactive contamination in inhabited areas: Radioactivity in the Environment vol. 15, edited by K.G. Andersson (Elsevier, Amsterdam, Netherlands, 2009 ), 107.

[11] IAEA. IAEA TECDOC-1616. International Atomic Energy Agency, Vienna, Austria, (2009). 